\title{
AN INVESTIGATION OF STUDENT DEFINITIONS AND VALUE OF CREATIVITY IN ENGINEERING EDUCATION
}

\author{
David R. Waller, M.A.Sc (Candidate) and David S. Strong, Professor \& NSERC Chair in Design Engineering \\ Faculty of Engineering and Applied Science, Queen's University, Ontario, Canada \\ david.waller@queensu.ca $\mid$ strongd@queensu.ca
}

\begin{abstract}
There appears to be an existing disconnect between engineering education and creativity that is partly caused by a lack of understanding of creativity's role in engineering as well as the lack of value placed on creativity in the academic environment. This paper used mixed methods research to investigate this disconnect through the perceptions of undergraduate engineering students. A survey was used to gather definitions of engineering creativity and to measure the value students place on creativity in engineering.

Results indicated that students have a wide variety of definitions and understanding of engineering creativity. It was found that students generally valued creativity in an engineering context, but Year 4+ students had statistically significant less value for creativity than all other years of study. The findings support the need for a well-developed and universally accepted definition of engineering creativity. Causation for the difference in value Year 4+ students place on engineering creativity should be further investigated.
\end{abstract}

Keywords: creativity, innovation, definition of creativity, value for creativity, higher education, student perceptions, engineering education

\section{INTRODUCTION}

Creativity has been recognized as an essential skill for engineers and is required to generate innovative solutions to society's increasingly complex problems. Cropley distinguishes between two types of problem solving: (a) routine and (b) creative. Routine problem solving occurs when problems are approached using traditional and wellestablished methods. Though routine problem solving plays an important role in engineering, it does not often result in innovation. Conversely, creative problem solving is required to effectively solve the challenges brought on by a changing environment and world. This occurs through "redirection" where newly discovered methods and technologies create opportunities to address new problems, and "reinitiation" where problems can only be satisfied with the development of new methods and technologies [6].

Many current engineering education programs focus on routine replication where the engineering process follows a precedence that is well-defined in the field of study. Students in such programs are not given many opportunities to improve their creativity skills which will help them become future innovators. This is an important consideration because innovative engineering is essential for developing a competitive economy [12].

Cropley goes on to argue that there is currently a disconnect between engineering and education. Part of this disconnect is rooted in a lack of knowledge and value for creativity in engineering education. In order to successfully embed creativity in the engineering curriculum, these disconnects need to be understood and reconciled [6].

\subsection{Purpose of Research}

Teaching and learning latent constructs such as creativity is challenging because of the difficulty of establishing clear definitions that are consistently used in various fields of study. This becomes a larger problem when definitions are domain-specific, as in the case of engineering creativity. Before engineering students can be expected to demonstrate and develop creativity skills, they need to understand how creativity, in a specific engineering context, is defined. When definitions of creativity are not cohesive, students may attempt to generate designs or solutions that are not aligned with accepted characterizations of engineering creativity.

Once students have a clear understanding of what is expected when they are asked to demonstrate engineering creativity in their course work, motivation becomes a concern. According to expectancy-value theory, if students do not value creativity skills, they will not have the motivation to learn them, resulting in underdeveloped creative abilities which have been shown to be essential to successful practicing engineers [18].

This research study aims to address the disconnects of a lack of understanding and value for engineering creativity by investigating them through student 
perceptions. This paper is a subset of a larger inquiry into the creativity environment in undergraduate engineering education. The following research questions that guide this study are:

1. How do engineering students define creativity in an engineering context?

2. How do engineering students in different years of study value creativity?

\subsection{Literature Review}

Creativity has a multitude of different definitions in the education and psychology literature. Sternberg's Handbook of Creativity identified 61 different ways in which creativity can be defined [16]. A content analysis of creativity literature in the fields of psychology and education by Plucker, Behetto, and Dow concluded that $62 \%$ of articles did not explicitly define creativity while the remaining $38 \%$ varied considerably in their definitions [11].

This problem is compounded by the supposition that creativity is context specific [14]. Particularly in the engineering education literature, many researchers initiate discussions of engineering creativity by claiming that it is a poorly defined term and subsequently propose their own definition [6]. A special issue of the European Journal of Engineering Education on engineering creativity contained 13 articles, each with a unique definition of the term [19]. Furthermore, Zappe, Mena, and Litzinger's study investigated 16 engineering education articles on the topic of creativity and found that there was no consistent definition of the term, but there were common themes of problem solving, uniqueness, and functionality [17].

A recent study by Marquis and Henderson gathered definitions of creativity from instructors of various subjects at Ontario universities. Their analysis of these definitions led to conclusions that most creativity definitions had common themes that aligned with classical definitions of creativity, that being the creation of something that is novel. They also noted that other respondents focused on modes of thought that embodied creative thinking. Though they argued that the majority of their results indicated that definitions of creativity were not subject specific, some instructors, particularly those in engineering and science, did perceive a unique type of subject specific creativity [7].

When considering value for creativity, there is a consensus in the literature that creativity is of value to engineering design and education [3] [4]. However, Kazerounian and Foley found that while engineering students felt that creativity was a valuable skill for engineers, they did not feel that their instructors valued creativity in the academic setting. Conversely, when surveying engineering faculty, they found that instructors did report value for creativity [12]. This study highlights the disconnect between creativity and engineering education.

On the other hand, a study by Atman, Kilgore, and McKenna found that only $30 \%$ of engineering students in upper years valued creativity in their design work. They suggested that developing a unique engineering creativity definition will help promote value for creativity skills, as generic creativity terms tend to constrain the thinking and understanding of creativity with respect to the engineering design process [5].

\section{STUDY DESIGN}

\subsection{Methodology}

The first research question was approached using mixed methods with a phenomenological framework. Creswell describes phenomenology as a methodology that explores the meaning of the lived experiences of a group of individuals towards a concept or phenomenon [10]. In this study, the phenomenon under consideration was how undergraduate engineering students understand the meaning of engineering creativity. Mixed methods was appropriate to quantify the large number of definitions that were collected from the sample population.

For the second research question, an ex-post facto and independent factorial design was used. The comparative group for this design was year of study in undergraduate engineering and the dependent variable was value students place on creative thinking skills.

\subsection{Sampling}

A combination of convenience sampling and proportional stratified sampling was used in data collection. Queen's University undergraduate engineering students were used as the sample population because of convenient accessibility. Students from all engineering disciplines and years of study were invited to participate in the survey. The Queen's University undergraduate engineering curriculum introduces students to creative thinking concepts in their design spine courses during first and second year. These concepts are also expanded upon in a few upper year engineering design courses. The survey was distributed through email to undergraduate engineering students at Queen's University upon ethics approval, and core classes for each engineering discipline were visited to promote the survey when given permission from the course instructor.

Proportional stratified sampling was used within this sample population to have approximately equal group sizes for each year of study in order to make within-group comparisons. After data cleanup, 504 responses were used for the analysis, representing a $17.1 \%$ return rate, based on a total of 2,946 undergraduate engineering students at 
the beginning of the 2015-16 academic year [15]. Of these 504 responses, 416 provided written definitions of engineering creativity representing $14.1 \%$ of the sample population.

\subsection{Instrument}

A survey was used for data collection consisting of both open-ended and closed-ended items. The survey contained eight open-ended survey items, one of which asked participants to provide a written definition of creativity in an engineering context. This was the item of interest for the study's first research question.

Closed-ended items were adapted from a survey developed by Basadur and Hausdorf [13]. The 18 item survey was initially designed to measure attitudes towards creative thinking of employees in large corporations. Items were modified for an engineering education context and two extra items were included specific for engineering students. Items were measured on a 5-point Likert scale from "Strongly Disagree" to "Strongly Agree". One of the factors measured by this survey was "Valuing New Ideas" which was measured using 11 items. For this factor, internal consistency was determined using Cronbach's alpha. Values of .70 $(n=210)$ and .70 $(n=98)$ were reported on two separate administrations of the survey with employee samples. Student samples were also tested and resulted in Cronbach's alpha values of .71 $(n=389)$ and $.76(n=319)$ for each respective administration of the survey [13].

\section{ANALYSIS}

\subsection{Research Question 1}

Qualitative data was analyzed using the constant comparative analysis described by Hewitt-Taylor [8]. This method of analyzing qualitative data used inductive techniques where the data generated the codes rather than using predetermined codes from a defined theory. Codes were applied to sentences and phrases of the definitions collected from the open-ended survey question as necessary. Codes were initially written on hard copies of the survey transcripts and their associated definitions were recorded in a separate digital file. Upon completion of coding, similar codes were gathered together to formulate categories and a frequency analysis was completed to determine the most common categories [2].

\subsection{Research Question 2}

For quantitative data, factor analysis was used to determine the latent constructs being measured by the survey and the items contributing to each factor. Internal consistency was estimated using Cronbach's alpha. Factor scores were calculated using equal weighting averages for all relevant factor items. Factor means and standard deviations were used to get sense of how each year of study responded and the variability of responses. Oneway ANOVA was used to determine if there were any statistically significant differences between years of study using an alpha of .05 (95\% confidence interval). Least Significant Difference (LSD) post-hoc testing was used to determine which groups were significantly different. LSD tests all possible pair-wise comparisons of means. Partial eta squared was used to estimate the effect size of any significant differences [1].

\section{RESULTS}

\subsection{Research Question 1}

The codes generated from constant comparison analysis of engineering creativity definitions were grouped into 15 categories. From these categories, two themes clearly emerged. Most definitions of creativity had an action describing the creative process, with associated characteristics describing what makes an idea or solution creative. The themes, categories, and frequency of each category are shown in Table 1.

Table 1: Constant comparison results for engineering creativity definitions $(n=416)$

\begin{tabular}{|c|c|c|}
\hline Theme & Category & Frequency (\%) \\
\hline \multirow[t]{6}{*}{ Action } & Problem solving & $204(49.0)$ \\
\hline & Ideation & $153(36.8)$ \\
\hline & $\begin{array}{l}\text { Thinking outside } \\
\text { the box }\end{array}$ & $107(25.7)$ \\
\hline & Critical thinking & $61(14.7)$ \\
\hline & Designing & $55(13.2)$ \\
\hline & Modification & $46(11.1)$ \\
\hline \multirow[t]{9}{*}{ Characteristic } & Novel & $152(36.5)$ \\
\hline & Unique & $151(36.3)$ \\
\hline & Unobvious & $63(15.1)$ \\
\hline & Functional & $58(13.9)$ \\
\hline & Innovative & $45(10.8)$ \\
\hline & Improvement & $33(7.9)$ \\
\hline & Complex & $23(5.5)$ \\
\hline & Simple & $18(4.3)$ \\
\hline & Abstract & $17(4.1)$ \\
\hline
\end{tabular}

The results indicated that students primarily associated engineering creativity with problem solving and idea generation processes. Students also described creative results as being predominantly novel and unique in nature. 


\subsection{Research Question 2}

For factor analysis, principal axis extraction and direct oblimin rotation were used because of non-random sampling and sample sizes that were not too large. Only factors with eigenvalues greater than one were retained in the analysis. The first factor identified through the analysis was "Value for creativity", confirming the similar factor from Basadur and Hausdorf's study [13]. This factor consisted of seven items and had a Cronbach's alpha of .65. Table 2 shows the means and standard deviations for "Value for creativity" for each year of study.

Table 2: Descriptive statistics for "Value of creativity" by year of study

\begin{tabular}{|l|c|c|}
\hline \multicolumn{1}{|c|}{ Year of Study } & Mean & SD \\
\hline Year $1(n=113)$ & 4.11 & .38 \\
\hline Year $2(n=131)$ & 4.11 & .40 \\
\hline Year 3 $(n=152)$ & 4.10 & .52 \\
\hline Year 4+ $(n=108)$ & 4.07 & .43 \\
\hline
\end{tabular}

The results of the one-way ANOVA indicated statistically significant differences between group levels for "Value for creativity" with a small effect size, $F(3,500)=5.29, p<.05, \eta^{2} .03$. LSD post-hoc testing indicated significant differences between Year $4+$ and Year $1(p=.001)$, Year $4+$ and Year $2(p=.001)$, and Year $4+$ and Year $3(p=.001)$.

\section{DISCUSSION}

\subsection{Definition of Creativity}

Engineering students provided definitions that were typically comprised of an action and characteristic. This is consistent with Feldhusen and Goh who stated that definitions of creativity require an associated cognitive activity [9]. It was found that research participants primarily associated this cognitive task with problem solving, ideation, and thinking outside the box. There were also several respondents who focused on the actions of critical thinking, designing, and modifying existing ideas. This is noteworthy because all of these actions relate to language used when describing engineering design [5]. This suggests that engineering students recognized the connection between engineering design and creativity.

However, it is worth mentioning that many responses were limited to one or two of the action categories. This may indicate that students felt creativity only applies to certain aspects of the design process while other aspects were perceived as not being conducive to a creative approach. This is concerning as students may feel being creative in engineering is isolated to specific steps in the design process, narrowing the scope of their application of creativity.

Of particular interest within this theme is the connection between critical thinking and creativity. Though critical thinking is an important aspect of creativity in an engineering context, it does not necessarily mean that critical thinking will always lead to creativity. This may suggest that students feel they are developing creativity skills when their course work calls for critical thinking, when in reality their tasks are more associated with routine replication. Still, it is encouraging that some students recognized that creativity does not come easily and requires thinking about engineering problems from different perspectives.

The most common characteristics of creative outputs were novelty and uniqueness of ideas. This aligns with many classical definitions of creativity, however it may pose challenges to engineering students who feel pressure to generate completely new ideas when they have not yet developed the technical expertise to do so [16]. Though these are important aspects of creativity, they may lean more towards innovation than creativity.

Some students also recognized that creative results demonstrate qualities of being unobvious, functional, and improvement. These elements are all related to context specific engineering creativity definitions, though it was concerning that fewer respondents identified these specific characteristics [6].

It was also interesting to note that some students perceived creative ideas as needing to be complex while others felt creative ideas were simple. This may have implications when asking students to be creative in their course work where students' understandings of their expectations may be contradictory which can pose challenges, particularly for team based projects. This can potentially be remedied by communicating a clear and universally accepted definition of engineering creativity to engineering students.

\subsection{Value for Creativity}

From the survey responses, it was clear that the typical engineering student at the institution studied recognized the value of creativity in the field of engineering. This was consistent across all years of study. However, Year $4+$ students did have statistically significant less value for creativity than all other years of study with a small effect size. This was an intriguing finding as it was expected that with more exposure to engineering, the value for creativity would have increased. Though this study does not explain causation for this significant difference, there are several potential explanations for this result.

There may be something inherent in the engineering education curriculum that is causing this difference. Many students in their final year of engineering participate in 
design courses which is where students feel creativity primarily applies. It is possible that the nature of the projects they work on are not providing enough opportunity for creativity. There is also the possibility that students feel being creative in their work may potentially result in lower grades if their designs are ultimately unsuccessful, implying that it is not worth taking the risk to try something creative. Therefore, the types of design projects and the nature of the assessment may be influential [12].

Another consideration is that students may have responded to the survey questions in relation to their course work, where being creative may not be as valuable as it would be in industry where success is measured differently than in an academic environment.

\section{CONCLUSIONS}

This study addressed the disconnects of creativity and engineering education by using a survey to explore student understandings and perceptions of engineering creativity. It was confirmed that students hold a wide variety of definitions of engineering creativity and is consistent with the many definitions found in the literature. To enhance these findings, it would be beneficial to complete a study where definitions of engineering creativity are collected from industry professionals, engineering professors, and engineering students to develop a universally accepted definition of engineering creativity. This may encourage students to develop the creative skills necessary to be successful as future engineers.

The significant difference between Year 4+ students are all other years of study should be further investigated. If reasons for this significant difference can be deduced, it will inform potential interventions to ensure that engineering students continue to have a high value for creative skills as they enter the workforce.

As this study was only conducted at Queen's University, it is recommended that the research be expanded to other Canadian universities to identify commonalities and differences in how students define and value engineering creativity based on institution. Through a clear understanding of each universities engineering courses and curriculums, best practices for promoting creativity in engineering can be established.

\section{Acknowledgements}

The authors gratefully acknowledge support of this research through funding from the NSERC Chair in Design Engineering program and the Ontario Graduate Scholarship, as well as the cooperation of the Faculty of Engineering and Applied Science at Queen's University. Special thanks to the students who participated in the research.

\section{References}

[1] Andy Field, Discovering Statistics Using IBM SPSS Statistics. Los Angeles, CA: SAGE Publications Inc., 2014 ( $4^{\text {th }}$ ed.), 915 pp.

[2] Anthony J. Onwuegbuzie and Charles Teddlie, Handbook of Mixed Methods in Social and Behavioral Research. Thousand Oaks, CA: SAGE Publications Inc., 2003 ( $1^{\text {st }} \mathrm{ed}$.), 748 pp.

[3] Chi-Kuang Chen and Kuang-Yaio Hsu, "Creativity of engineering students as perceived by faculty: A case study," International Journal of Engineering Education, vol. 22, no. 2, pp. 264-272, 2006.

[4] Christine Charyton and John A. Merrill, “Assessing general creativity and creative engineering design in first year engineering students," Journal of Engineering Education, vol. 98 , no. 2, pp. 145-156, 2009.

[5] Cynthia J. Atman, Deborah Kilgore, Ann McKenna, "Characterizing design learning: A mixed-methods study of engineering designers' use of language," Journal of Engineering Education, vol. 97, no. 3, pp. 309-326, 2008.

[6] David H. Cropley, "Promoting creativity and innovation in engineering education," Psychology of Aesthetics, Creativity, and the Arts, vol. 9, no. 2, pp. 161-171, 2015.

[7] Elizabeth Marquis and Jeremy A. Henderson, "Teaching creativity across disciplines at Ontario universities," Canadian Journal of Higher Education, vol. 45, no. 1, pp. 148-166, 2015.

[8] Jaquelina Hewitt-Taylor, "Use of constant comparative analysis in qualitative research," Nursing Standard, vol. 15, no. 42, pp. 39-42, 2001.

[9] John F. Feldhusen and Ban E. Goh. "Assessing and accessing creativity: An integrative review of theory, research, and development," Creativity Research Journal, vol. 8, no. 3, pp. 231-247, 1995.

[10] John W. Creswell, Qualitative Inquiry and Research Design: Choosing Among Five Approaches. Los Angeles, CA: SAGE Publications Inc., 2013 ( $3^{\text {rd }}$ ed.), 448 pp.

[11] Jonathan A. Plucker, Ronald A. Beghetto, and Gayle T. Dow, "Why isn't creativity more important to educational psychologists? Potentials, pitfalls, and future directions in creativity research," Educational Psychologist, vol. 39, no. 2, pp. 83-96, 2004.

[12] Kazem Kazerounian and Stephany Foley, "Barriers to creativity in engineering education: A Study of instructors and students perceptions," Journal of Mechanical Design, vol. 129, no. 7, pp. 761-768, 2007.

[13] Min Basadur and Peter A. Hausdorf, "Measuring divergent thinking attitudes related to creative problem solving and 
innovation management," Creativity Research Journal, vol. 9, no. 1 , pp. 21-32, 1996.

[14] Norman Jackson, Martin Oliver, Malcolm Shaw, James Wisdom, Developing Creativity in Higher Education: An Imaginative Curriculum. New York, NY: Routledge Abingdon, 2006 ( $1^{\text {st }}$ ed. $), 256$ pp.

[15] Queen's University Senate, 2015-16 Enrolment Report. Kingston, ON: Queen's University, 2015, 12 pp. Available as of May 6, 2016 from http://www.queensu.ca/registrar/ resources/reports

[16] Robert J. Sternberg. Creativity: A Handbook for Teachers. Singapore: World Scientific Publishing Company, 2007 ( $1^{\text {st }}$ ed.), $648 \mathrm{pp}$.
[17] Sarah Zappe, Irene Mena, and Thomas Litzinger, "Creativity is not a purple dragon," in Proc. NCIIA's 17th Annual Conference (Washington, DC; 22-23 March 2013), 13 pp., 2013.

[18] Shulamith Kreitler and Hernan Casakin, "Motivation for creativity design students," Creativity Research Journal, vol. 21, no. 2-3, pp. 282-293, 2009.

[19] Susanne Ihsen and Brandt Dietrich, "Editorial: Creativity: How to educate and train innovative engineers," European Journal of Engineering Education, vol. 23, no. 1, pp. 3-4, 1998. 